\title{
Serum Level of Vitamin D and Autoantibodies Level in Systemic Lupus Erythematosus ( SLE ) Patients
}

\author{
Kusworini Handono ${ }^{1}$, Agus Abdul $\mathrm{Gani}^{2}$, Mery Ekawati ${ }^{3}$, Singgih Wahono ${ }^{4}$ \\ 1, 2,3 Immunology Division, Department of Clinical Pathology, ${ }^{4}$ Rheumato-Immunology Division, Department of \\ Internal Medicine, Faculty of Medicine,Brawijaya University, Malang, Indonesia
}

\begin{abstract}
The involvement of vitamin D has been reported in immune response regulation, especially to inhibit $B$ cell differentiation and activation. The objective of our study was to determine the association between serum vitamin D level with the concentration of anti-dsDNA, anti-Sm, IgG-IgM anti-cardiolipin and anti-vitamin D antibodies in SLE patients in Dr Saiful Anwar Hospital, Malang.

Our subjects were fifty four female SLE (ACR 1992 revised criteria) out patients recruited from the Rheumato-Immunology Division, Dr Saiful Anwar Hospital, Malang, from January-June 2011. The mean age of the patients was 31.12 years (12-55 yo), duration of illness was 18,4 months (2-54 mo). ELISA method was used to assesessed serum vitamin $D\left[25(\mathrm{OH}) D_{3}\right]$ level, anti-dsDNA, anti-Sm, IgG - IgM ACA and anti-vitamin D antibodies. Correlation of serum vitamin $D$ and autoantibodies level were analyzed using Pearson correlation test.

Our study showed that $70.63 \%$ of SLE patients had low vitamin D serum level ( $<30 \mathrm{ng} / \mathrm{mL}$ ). We found the frequency of the positive antibodies as follow: anti-dsDNA in $70.30 \%$, anti Sm in $35.55 \%$, anti IgG ACA in $21.15 \%$, anti IgM ACA in $25 \%$ and anti vitamin D in $64.81 \%$. Serum level of $25(\mathrm{OH}) D_{3}$ was negatively correlated to the level of anti-dsDNA and anti-vitamin D antibodies ( $r:-0.416, p: 0.032$ and $r:-0.537, p: 0.041$ respectively). There was no correlation between serum level of vitamin D with ACA and anti Sm antibodies.

The low level of vitamin D in patients with SLE was related to anti-dsDNA and anti-vitamin D antibodies production. The low level of serum vitamin D in patients with SLE may be caused by the presence of anti vitamin D antibody.
\end{abstract}

Key Words. Vitamin D, 25(OH)D3, anti-dsDNA, anti-Sm, ACA, anti-vitamin D, SLE

\section{Background}

Systemic Lupus Erythematosus (SLE) is a systemic autoimmune disease with increased prevalency in the recent years. Although the 10 years life expectancy of patients with SLE in developed countries increase to 90\%, a study by Handono reported that Indonesian SLE patients have a low life expectancy, $70 \%$ within 5 years and 55\% within 10 years [1]. SLE is characterized by an immune response against nuclear antigens, and immune complexses deposition in target organ causing inflammation and tissue damages. Failure of T-cell tolerance toward self-antigens in genetically predisposed individuals and subsequent production of autoantibodies are the likely factors involved in the pathogenesis of the disease [2].

It has been known that one of the extraskeletal functions of vitamin $\mathrm{D}$ is involved in the regulation of immune responses. Various studies have reported the association between low serum levels of vitamin D with increasing incidence of autoimmune diseases including SLE [3]. There is a negative correlation between vitamin D serum concentration with disease activity, increase B cell proliferation and production of autoantibodies in patients with SLE [4,5,6]. Lack of sun exposure is reported to be the main cause of vitamin D deficiency in Caucasians [7]. Our previous study found that the clinical manifestations of Indonesian SLE patients were different from that reported in Caucasians. Indonesian SLE patients showed a more severe, more frequent anti-dsDNA antibody and photosensitivity [1]. The objective of our study was to determine the correlation between the serum level of vitamin D with anti-dsDNA, anti-Sm, anti-cardiolipin and anti-vitamin D antibodies concentrations in Indonesian SLE patients.

\section{Research Methods}

Subjects were fifty four newly diagnosed female SLE patients (diagnosis based on the ACR 1992 revised criteria) from Rheumato-Immunology Division, Department of Internal Medicine, Dr Saiful Anwar Hospital Malang, Indonesia. Activity of the disease was evaluated using Desease Activity Index Score (SLEDAI). Subyects included in this study had SLEDAI score $>5$ and did not consume vitamin D before. The study was approved by the Ethics Committee of the Faculty of Medicine, Brawijaya University and informed consent was obtained from all participants. Serum were collected and store in $-80^{\circ} \mathrm{C}$ until used to measure the cocentration of vitamin D [25(OH)D3] (Cusabio, China), anti-ds DNA, anti-Sm, IgG-IgM anti-cardiolipin IgGIgM ACA (Diagnostic Automation,USA) by ELISA in accordance with the manufacturer's instruction and anti- 
vitamin D antibodies by ELISA (developed by our own laboratory, KH and EM ). All samples were assyed in duplicate.

\section{The Principle Assay of Vitamin D [25 (OH) D3]}

Prepared 96 microplate wells that had been coated with anti-vitamin D antibodies (Cusabio, China), 200 $\mu \mathrm{l}$ of serum samples was added that had been diluted before, incubation at $18-25^{\circ} \mathrm{C}$ for 2 hours. Wash all wells 3 times with washing buffer and than add with $200 \mu \mathrm{lenzyme} \mathrm{conjugate,} \mathrm{incubation} \mathrm{at} 18-25^{\circ} \mathrm{C}$ for 30 minutes. Wash 3 times with washing solution, add $200 \mu \mathrm{l}$ TMB substrate to all wells, incubation of $18-25^{\circ} \mathrm{C}$ for 30 minutes. Add $100 \mu \mathrm{l}$ stop solution to all wells. Measure the absorbance at $450 \mathrm{~nm}$ using a spectrophotometer within $30 \mathrm{~min}$ after the addition of stop solution. Vitamin D levels considered as normal when the concentration $>30 \mathrm{ng} / \mathrm{ml}$; insufficiency : $15-30 \mathrm{ng} / \mathrm{ml}$ and deficiency $<15 \mathrm{ng} / \mathrm{ml}[8]$.

\section{The Principle Assay of Autoantibodies}

Synthetic antigen, previously attached to the microplate wells (Diagnostic Automation, USA). $100 \mu$ of diluted serum samples added to the wells, incubated for 45 minutes. Anti human $\operatorname{IgG}$ antibodies that have been labeled with HRP enzyme was added after the washing process and than incubation with the substrate. Color intensity was measured using a $450 \mathrm{~nm}$ spectrophotometer. Levels of anti-dsDNA concidered as negative when the concentration $<92 \mathrm{IU} / \mathrm{ml}$, anti-Sm $<20 \mathrm{IU} / \mathrm{ml}, \mathrm{IgG} \mathrm{ACA}<15 \mathrm{GPL} / \mathrm{ml}$ and IgM ACA $<15 \mathrm{MPL} / \mathrm{ml}$.

\section{The Principles Assay of Anti-Vitamin D Antibody}

$50 \mu \mathrm{l}$ of antigen vitamin $\mathrm{D}(20 \mathrm{ng} / \mathrm{ml})$ which had been diluted with coating buffer attached to the micro plates well, incubated at $4{ }^{\circ} \mathrm{C}$ overnight. Wash the wells with washing buffer, add $50 \mu l$ of each standard solution were prepared and diluted serum samples, incubated for 2 hours.. Add $50 \mu$ of the anti human IgG antibody that has been labeled with HRP enzym, incubated for 1 hour. Incubation with $100 \mu 1$ of TMB substrate after the washing process. Color intensity was measured using a $450 \mathrm{~nm}$ spectrophotometer. Cut off level of anti-vitamin D were determined by comparing the levels in 20 samples of healthy control (> mean $+2 \mathrm{SD}$ ). Normal values of anti vitamin D antibody was concidered if the concentration $<1.5 \mathrm{ng} / \mathrm{ml}$.

\section{Statistical Analysis}

Differences the levels of anti-ds DNA, anti-Sm, IgG-IgM ACA and anti-vitamin D antibodies of the SLE patients with vitamin $\mathrm{D}$ insufficiency and deficiency were analyzed by indipendent $\mathrm{T}$ test. Correlation of vitamin D levels with anti-dsDNA, anti-Sm, IgG-IgM ACA and anti-vitamin D antibodies concentration were analyzed by Pearson correlation test. Statistical significance was determined if $\mathrm{p}$ value $<0.05$.

\section{Results}

Our studied in fifty four women SLE patients revealed that the mean age of the patients was 31.12 years (12-55 years), with duration of illness was 18.4 months (2-54 mo). Most of the patients studied complaint arthritis, malar rash and photosensitivity (45-68\%, data not shown). The mean levels of vitamin D was $22.80 \pm$ $16.23 \mathrm{ng} / \mathrm{ml}$ (normally $>30 \mathrm{ng} / \mathrm{ml}$ ). The mean levels of anti-ds-DNA was $142.571 \pm 79.73 \mathrm{IU} / \mathrm{ml}$ (cut off $<92$ $\mathrm{IU} / \mathrm{ml}$ ), anti-Sm : $19.34 \pm 22.59 \mathrm{IU} / \mathrm{ml}$ (cut of $<20 \mathrm{IU} / \mathrm{ml}$ ), IgM ACA was $16.97 \pm 23.32 \mathrm{MPL} / \mathrm{ml}$ (cut of < 15 $\mathrm{MPL} / \mathrm{ml}$ ), IgG ACA was $12.61 \pm 19.33 \mathrm{GPL} / \mathrm{ml}$ (cut of $<15 \mathrm{GPL} / \mathrm{ml}$ ) and levels of anti-vitamin D was $3.22 \pm$ $1.34 \mathrm{ng} / \mathrm{ml}$ (cut of $1.5 \mathrm{ng} / \mathrm{ml}$ ).

\section{Vitamin D And Autoantibodies In SLE Patients}

Our study shown that $20.37 \%$ of SLE patients had normal vitamin D serum level, $24.7 \%$ with insuffisiency and $55.56 \%$ with deficiency of vitamin D. Subyects with high levels of anti-ds DNA (>92 IU/ml) found in $70.3 \%$, with high level of anti-Sm $(>20 \mathrm{IU} / \mathrm{ml})$ found in $35.55 \%$, IgM ACA $(>15 \mathrm{MPL} / \mathrm{ml})$ found in $25 \%$, IgG ACA ( $>15 \mathrm{GPL} / \mathrm{ml})$ found in $21.15 \%$ patients and anti-vitamin D $(>1.5 \mathrm{ng} / \mathrm{ml})$ found in $64.81 \%$ patients (Table 1).

Table 1. Vitamin D level and autoantibodies in SLE patients

\begin{tabular}{cc}
\hline LES, N $=\mathbf{5 4}$ & $\mathbf{\%}$ \\
\hline Normo vitamin D $(>30 \mathrm{ng} / \mathrm{mL})$ & 20,37 \\
Vitamin D insufficiency $(20-30 \mathrm{ng} / \mathrm{mL})$ & 24,7 \\
Vitamin D deficiency $(<20 \mathrm{mg} / \mathrm{mL})$ & 55,56 \\
Anti-ds DNA positive $(>92 \mathrm{IU} / \mathrm{mL})$ & 70,3 \\
Anti-Sm positive $(>20 \mathrm{IU} / \mathrm{mL})$ & 35,55 \\
ACA IgG positive $(>15 \mathrm{GPL} / \mathrm{mL})$ & 21,15 \\
ACA IgM positive $(<15 \mathrm{MPL} / \mathrm{mL})$ & 25 \\
Anti-vitamin D positive $(>1.5 \mathrm{ng} / \mathrm{mL})$ & 64,81 \\
\hline
\end{tabular}


Serum Level Of Vitamin D And Autoantibodies Level In Systemic Lupus Erythematosus ( SLE)

Differences the levels of autoantibodies in SLE patients with normo and hypovitamin D

There were significant differences the level of anti-dsDNA and anti vitamin D antibodies in SLE patients with normo and hypovitaminosis D. However, all antibodies concentration seemly tends to be higher in patients with hypovitaminosis D than in patients wth normo vitamin D (Table 2).

Table 2. Differences in the level of autoantibodies in the SLE patients with normo and hypovitamin D

\begin{tabular}{llll}
\hline \multicolumn{1}{c}{ Autoantibodi } & \multicolumn{1}{c}{$\begin{array}{c}\text { Normo Vit D } \\
\mathbf{N = 1 1}\end{array}$} & $\begin{array}{c}\text { Hypo Vit D } \\
\mathbf{N}=\mathbf{4 3}\end{array}$ & \multicolumn{1}{c}{ P } \\
\hline Anti-dsDNA (IU/ml) & $132,78 \pm 72,31$ & $145,07 \pm 91,01$ & $<0,05$ \\
Anti-Sm (IU/ml) & $17,46 \pm 16,99$ & $19,88 \pm 24,14$ & Ns \\
ACA IgM (MPL/ml) & $14,29 \pm 26,62$ & $17,69 \pm 22,67$ & Ns \\
ACA IgG (GPL/ml) & $11,59 \pm 24,54$ & $12,88 \pm 18,04$ & Ns \\
Anti-vitamin D (ng/ml) & $1,99 \pm 1,40$ & $2,79 \pm 1,33$ & $<0,05$ \\
\hline
\end{tabular}

$* \mathrm{P}<0.05$ : significantly

Although there were no significantly differences in the levels of all autoantibodies are shown in SLE patients with vitamin D insufficiency and vitamin D deficiency, however, SLE patients with vitamin D deficiency tend to be higher in secretion of autoantibodies (Table 3).

Table 3. Differences in the levels of autoantibodies in the SLE patients with vitamin D insufficiency and vitamin D deficiency

\begin{tabular}{llll}
\hline \multicolumn{1}{c}{ Autoantibodi } & \multicolumn{1}{c}{$\begin{array}{c}\text { Vit D Insufficiency } \\
\mathbf{N = 1 3}\end{array}$} & $\begin{array}{c}\text { Vit D Deficiency } \\
\mathbf{N = 3 0}\end{array}$ & \multicolumn{1}{c}{ P } \\
\hline Anti-dsDNA (IU/ml) & $140,89 \pm 96,53$ & $148,09 \pm 88,73$ & $\mathrm{Ns}$ \\
Anti-Sm (IU/ml) & $19,35 \pm 23,83$ & $20,08 \pm 24,74$ & $\mathrm{Ns}$ \\
ACA IgM (MPL/ml) & $14,33 \pm 20,26$ & $20,06 \pm 24,37$ & $\mathrm{Ns}$ \\
ACA IgG (GPL/ml) & $8,03 \pm 14,04$ & $16,32 \pm 19,97$ & $\mathrm{Ns}$ \\
Anti-vitamin D (ng/ml) & $2,06 \pm 1,30$ & $3,44 \pm 1,37$ & $<0.05$ \\
\hline \multicolumn{1}{c}{$*$ P $<0.05:$ significantly } & & &
\end{tabular}

Correlation between the level of Vitamin D and the levels of autoantibodies in SLE patients

There were significantly negative correlations between the level of vitamin D with the levels of antidsDNA, and vitamin D antibodies (Table 4).

Table 4. Correlation of vitamin D serum levels with autoantibodies in SLE patints

\begin{tabular}{lll}
\hline & \multicolumn{1}{c}{ Vitamin D } & \multicolumn{1}{c}{ P } \\
\hline Anti-dsDNA (IU/ml) & $\mathrm{r}:-0,41$ & $<0.032$ \\
Anti-Sm (IU/mL) & $\mathrm{r}:-0,23$ & $\mathrm{Ns}$ \\
ACA IgM (IU/ml) & $\mathrm{r}:-0,66$ & $\mathrm{Ns}$ \\
ACA IgG (IU/ml) & $\mathrm{r}:-0,08$ & $\mathrm{Ns}$ \\
Anti-vitamin D (ng/ml) & $\mathrm{r}:-0.53$ & $<0.041$ \\
\hline$* \mathrm{P}<0.05:$ significantly & &
\end{tabular}

\section{Discussion}

Our study shown that the mean levels of vitamin D in SLE patients was significantly lower campoare with healthy subjects . In general, serum level of vitamin D is influenced by several factors such as physical factor (clothing, use of sunscreen or sunglasses, altitude, season, time outdoors, etc.) and biological factors such as pigmentation, use of medication, thick body fat, fat malabsorption and age $[9,10]$. While it has been pointed out that vitamin D deficiency may increase the risk of autoimmune disease, SLE patients were suspected of having a variety of risk of deficiency of vitamin D.Low levels of vitamin D in patients with SLE may be caused by low nutritional vitamin D intake, the use of sunscreens, the lack of outdoor activities, use clothes that are closed, corticosteroid treatment and the presence of autoantibodies against vitamin D, vitamin D binding protein and to its receptor (VDR) [11]. SLE patients is often accompanied by decreased function of the kidneys, result in decreased of $1 \alpha$-hydroxylase that is essential for the manufacture of $25-\mathrm{OH}$ vitamin D. This certainly can aggravate the low level of vitamin D. In addition, patients often receive treatment hidroxychloroquine LES, which is thought to lower the conversion to the active form of vitamin D2. Furthermore, photosensitivity is a manifestation is often found in the LES, and avoiding sun exposure can also lead to impaired metabolism of vitamin D [9]. Finally, the presence of antibodies anti-vitamin D, which was detected in SLE patients with antiphospholipid syndrome as well as with anti-dsDNA, can lead to deficiency of vitamin D [3]. Our study showed 
Serum Level Of Vitamin D And Autoantibodies Level In Systemic Lupus Erythematosus ( SLE)

that $64.81 \%$ of patients had antibodies anti-vitamin $\mathrm{D}$, hence it needs to consider this as one as an important cause of low levels of vitamin D.

There is a bidirectional association between low level serum vitamin D and SLE. SLE can cause decreased serum level of the vitamin, but in the other hand low serum vitamin D may be related to incresased risk of autoimmunity and the severity of the diseases. The role of vitamin D and its active metabolites 1:25 (OH) 2D3 in modulating the immune response is based upon : the discovery of vitamin D receptor (VDR) on macrophages, activated $\mathrm{T}$ and $\mathrm{B}$ lymphocytes, the ability of activated macrophages, dendritic cells, $\mathrm{T}$ cells and B cells to express CYP27B1 enzyme producing 1:25 (OH) 2D3, and capability of 1:25 (OH) 2D3 in regulating cell proliferation and function of macrophages, dendritic cells, $\mathrm{T}$ and $\mathrm{B}$ cells with increased of autoanyibodies secretion $[12,13,14]$. The dysregulation of the immune cells will result in more irregularities of the immune system function that may related to disease activity of SLE in hypovitaminosis vitamin D. Our study showed that the mean levels of anti-dsDNA, and anti-vitamin D antibody in our patients with low serum vitamin D level were significantly higher compared to patients with normal vitamin D serum level.

Irastorza et al study which examined 92 patients with SLE white vitamin D deficiency was found that these patients showed higher levels of fatigue and a higher frequency photosensitivity. There is no association between vitamin D deficiency with duration of illness and the severity of the disease. Subsequently it was reported that vitamin D deficiency in SLE patients is associated with avoidance of sun exposure [3]. Various studies have been reported in SLE patients suggest an association between vitamin D with various clinical manifestations and abnormalities of the immune response. Kamen et al, reported that the levels of $25(\mathrm{OH}) \mathrm{D}$ LES 124 patients newly diagnosed Caucasian race appear lower than 240 healthy controls by age, sex and smoking habits are the same $(\mathrm{p}=0.04)$ [15]. Some 67\% of SLE subjects with vitamin D deficiency is pointed out that the African American race had average levels of vitamin D $(15.9 \mathrm{ng} / \mathrm{ml})$ lower than Caucasians (31.3 $\mathrm{ng} / \mathrm{ml})$. Vitamin D levels are very low $(<10 \mathrm{ng} / \mathrm{ml})$ obtained in 22 SLE patients who had manifestations of nephritis and photosensitive. These results indicate that vitamin D deficiency is a risk factor for SLE and require further research to determine the role of vitamin D in the prevention or treatment of patients with SLE [15]. Thud et al [16] reported that $20 \%$ of patients had levels of $25(\mathrm{OH})$ D lower than normal values $(<47.7 \mathrm{nmol} /$ L). SLE patients with low levels of vitamin D that have the disease activity scores were markedly higher than SLE patients with normal vitamin D levels $(\mathrm{p}<0.003)$. However, the study found that levels of anti-dsDNA autoantibodies is higher in SLE patients with low vitamin $\mathrm{D}>47.7 \mathrm{nmol} / \mathrm{L}(\mathrm{p}=0.0069)$. An increase in disease activity in SLE patients with vitamin D deficiency, indicating that vitamin D supplementation is expected to optimize treatment outcomes LES, but the possibility that administration of vitamin D will increase anti-dsDNA levels need further research [17].

\section{Conclusion}

Our study indicate that although Indonesian has lot of sun exposure, the mean level of vitamin D in SLE patients studied was low. Our study showed that one cause of low levels of vitamin D was the presence of antibodies anti-vitamin D. Low levels of vitamin D correlated with increase levels of anti-dsDNA, which suggests that vitamin D plays an important role in the regulation of the immune system, especially in inhibiting the activation of cell $\mathrm{B}$.

\section{Acknowledgment}

The Government of the Republic of Indonesia c/q Ministry of National Education, Research Development Unit Faculty of Medicine, Brawijaya University for funding this research.

\section{Conflict of Interests}

No conflict of interest has been declared by the authors

\section{References}

[1] Handono K. HLA klas II dan kerentanan genetik terhadap Lupus Eritematosus Sistemik di Indonesia. Acta Med Ind 2001; 32:1115.

[2] Jianxin J, Kwan CHB, Cheuk CS. Up date on the role T cell sub set in the pathogenesis of systemic Lupus Erythematous. The Chiness university Hongkong, Statin, Hongkong China $2009 ; 4(\&): 400-409$.

[3] Irastorza GR, Egurbide MV, Olivares N, et al. Vitamin D deficiency in systemic lupus erythematosus: prevalence, predictors and clinical consequences. Rheumatology 2008; 47:920-923.

[4] Adams JS and Hewison M. Unexpected actions of vitamin D: new perspectives on the regulation of innate and adaptive immunity. Nat Clin Pract Endocrinol Metab 2008; 4(2):80-90.

[5] Kuhn A, Beissert S, and Krammer PH. CD4+CD25+ regulatory T cells in human lupus erythematosus. Arch Dermatol Res 2009; $301 ; 17-81$.

[6] Toubi E and Shoenfeld Y. The role of vitamin D in regulating immune responses. IMAJ 2010;12:174-175.

[7] Szodaray P, Nakken B, Gaal J, et al. The complex role of vitamin D in autoimmune diseases. Scandinavian J Immunol 2008; 68:261-269.

[8] Cutolo M. Vitamin D and autoimmune Rheumatic disease. Rheumatol 2009; 48:210-213.

[9] Hollick MF. High prevalence of vitamin D inadequancy and implications for health. Mayo Clin Proc 2006; 87(supl):1080S-1086S. 
[10] Marco EC, Morales MM, Vila M, et al. Serum 25-hydroxyvitamin D levels in patients with cutaneous lupus erythematosus in a mediterranean region. Lupus 2010; 10:1-5.

[11] Carvalho JF, Blank M, Kiss E, et al. Anti-Vitamin D, Vitamin D in SLE. Preliminary Results. Ann. N. Y. Acad. Sci 2007; 1109:550-557.

[12] Bikle D. Nonclassic Actions of Vitamin D. J Clin Endocrinol Metab 2009; 94(1):26-34.

[13] Chen S, Sims GP, Chen XX, et al. Modulatory effects of 1,25-dihydroxyvitamin D 3 on human B cell differentiation. J. immunol 2007; 179:1634-1647.

[14] Askenasy N, et al. Mechanism of T regulatory Cell Function. Autoimmun Rev 2008; 7:370-375.

[15] Kamen DL, Cooper GS, Bouali H, et al. Vitamin D deficiency in systemic lupus erythematosus. Autoimmune Rev 2006; 5:114117.

[16] Thud A, Yin S, Wandstrat AE, Li QZ, Olsen NJ, 2008. Vitamin D levels and disease status in Texas patients with systemic lupus erythematosus. Am J Med Sci, Feb;335(2):99-104.

[17] Mouyis M, Ostor AJK, Crisp AJ, et al. Hypovitaminosis D among rheumatology outpatients in clinical practice. Rheumatol 2008; 47:1348-1351. 